\title{
A Preliminary Seismic Risk Assessment for Diqing, Yunnan
}

\author{
Changlong Li \\ Institute of Geophysics, China Earthquake Administration \\ Beijing 100081, China \\ changlongli@163.com \\ 云南迪庆地震损失风险的初步评估 \\ 李昌珑 \\ 中国地震局地球物理研究所 \\ 北京 100081, 中国 \\ changlongli@163.com
}

\begin{abstract}
Diqing is located in Northwestern Yunnan, where has many strong earthquakes. It is worth to study the seismic risk of Diqing. In this paper, we investigated the numbers, taxonomy and vulnerability of the buildings in Diqing and assessed the distribution of each type of buildings in every town. Then we made an scenario-based seismic risk assessment for the towns in Diqing. Our study indicated that if a M7.0 earthquake happened in Lijiang, it may cause serious casualties in Diqing with a casualty more than 1000 and more than 18000 houses destructed.
\end{abstract}

Key words: Diqing, Seismic risk, Building taxonomy, Structural Vulnerability

摘要-迪庆州位于云南西北部, 强震频繁, 地震风险值得研 究。本文基于迪庆的人口统计和建筑数据, 对州内的建筑进 行了类型划分及数量分配, 根据藏区建筑在几次大地震中的 震害资料建立了建筑的易损性模型，并对迪庆基于设定地震 的地震损失风险进行了初步评估。本文研究表明, 若丽江发 生 7.0 级地震, 可能造成迪庆州 3 区县千余人的伤亡, 可能有 1.8 万余间房屋受损。

关键词：迪庆；地震风险；建筑类型；结构易损性

I. 引言

迪庆藏族自治州位于云南省西北部, 活动断层分布 广泛, 历史上多次发生强震（图 1)，地震危险性很 高。同时, 迪庆州近年旅游业等产业快速增长, 成为国 内外关注的热点地区。因此, 迪庆州的地震风险是值得 研究的问题。近年来地震危险性和地震风险研究已在世 界范围内广泛开展 [1]。本文基于迪庆的人口统计和建筑 数据, 对州内的建筑进行了类型划分及数量分配, 根据 藏区建筑在几次大地震中的震害资料建立了建筑的易损 性模型, 并对迪庆基于设定地震的地震损失风险进行了 初步评估。

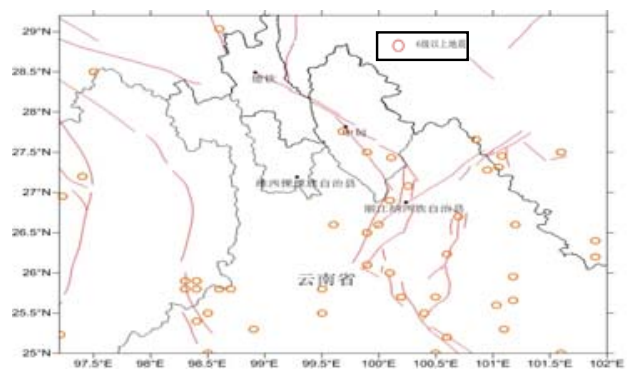

图 1 迪庆附近断层分布和历史上 $M \geqslant 6$ 地震分布图

\section{II. 迪庆人口数据}

迪庆州共有 3 个区县，人口分布数据来自第六次人口 普查和各县市的年度报告 $[2]$ 。可收集到的数据有每个县 的总人口和总户数, 以及城镇人口数和农村人口数。各 区县的城镇、农村人口和户数如表 1 所示。

表 1 迪庆各区县县城镇、农村人口及户数统计表

\begin{tabular}{ccccccc}
\hline 区县 & 户数 & $\begin{array}{c}\text { 最新人 } \\
\text { 口 }\end{array}$ & $\begin{array}{c}\text { 城镇人 } \\
\text { 口 }\end{array}$ & $\begin{array}{c}\text { 农村人 } \\
\text { 口 }\end{array}$ & $\begin{array}{c}\text { 城镇户 } \\
\text { 数 }\end{array}$ & $\begin{array}{c}\text { 农村户 } \\
\text { 数 }\end{array}$ \\
\hline $\begin{array}{c}\text { 香格里 } \\
\text { 拉市 }\end{array}$ & 39419 & 145265 & 26788 & 118477 & 7269 & 32150 \\
德钦县 & 13758 & 60081 & 7509 & 52572 & 1719 & 12039 \\
维西县 & 44370 & 154127 & 16410 & 137717 & 7006 & 37364 \\
合计 & 97547 & 359473 & 50707 & 308766 & 15994 & 81553 \\
\hline
\end{tabular}

III. 迪庆建筑结构分类和数量分布

迪庆州为藏族聚居区，该地区的建筑分类参考西藏 东南部的建筑类型, 即公建房、自建新房、老旧房、木 结构（图 2）。确定各区县各类型建筑的数量时，使用 西藏东南部的建筑数量分布的抽样考察结果[3], 如表 2 所示。将香格里拉市的城市户数按照市主城区的各类型 建筑比例分配, 农村户数按照市郊农村的比例分配; 德 钦县和维西县的城市人口按照县城城区的比例分配。考 虑到迪庆州位于横断山区，与藏东南木结构分布区自然 条件类似，因此将德钦县与维西县的农村户数按照藏东 南木结构分布区的县辖乡村的比例分配。各区县各类型 建筑数量分布如表 3 所示。 


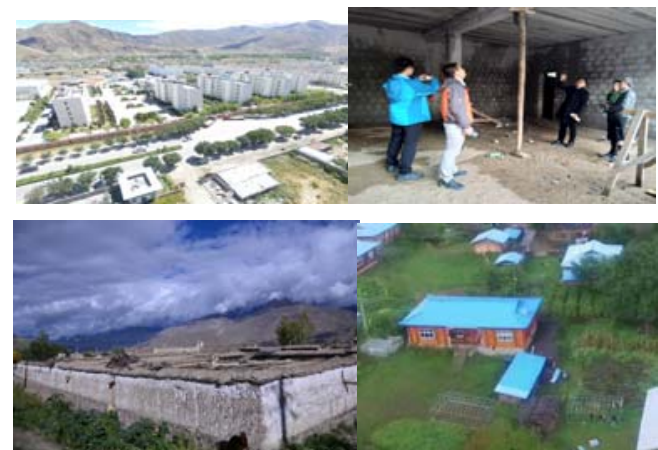

图 2 四种房屋建筑类型典型图 (上左: 公建房; 上右: 自建新 房; 下左: 老旧房; 下右: 木结构。资料来源: 中国地震局地 球物理研究所地震保险项目组)

表 2 建筑数量统计抽样地区

\begin{tabular}{c|c}
\hline 城乡类型 & 抽样地区 \\
\hline 市主城区 & 山南市乃东区 \\
市郊乡村 & 拉萨市城关区娘热乡 \\
县城城区 & 拉萨市曲水县才纳乡 \\
县辖乡村 & 林芝市鲁朗镇 \\
木结构分布区 & 波密县岗堆村、米林县帮加村 \\
\hline
\end{tabular}

表 3 迪庆州各县各类型建筑总数统计表

\begin{tabular}{c|c|c|c|c|c|c|c|c}
\hline 区县 & $\begin{array}{c}\text { 公建 } \\
\text { 房 }\end{array}$ & $\begin{array}{c}\text { 自建新 } \\
\text { 房 }\end{array}$ & 老旧房 & 木结构 & $\begin{array}{c}\text { 公建房 } \\
\text { 人口 }\end{array}$ & $\begin{array}{c}\text { 自建新 } \\
\text { 房人口 }\end{array}$ & $\begin{array}{c}\text { 老旧房 } \\
\text { 人口 }\end{array}$ & $\begin{array}{c}\text { 木结构 } \\
\text { 人口 }\end{array}$ \\
\hline $\begin{array}{c}\text { 香格里 } \\
\text { 拉市 }\end{array}$ & 8113 & 17402 & 13904 & 0 & 29896 & 64129 & 51240 & 0 \\
\hline 德钦县 & 1421 & 2216 & 3925 & 6196 & 6206 & 9677 & 17140 & 27059 \\
维西县 & 5446 & 7309 & 12383 & 19231 & 14233 & 24505 & 44506 & 70883 \\
\hline
\end{tabular}

为计算地震造成的人员伤亡率, 将各区县的人口按 照建筑数量的比例分配到各建筑类型上, 也列在表 3 中。

\section{IV.易损性模型}

对第 2 章的四种建筑类型建立易损性模型。建立方 法主要基于西藏及周边地区近年来地震灾害的震害统计 资料, 如 2010 年青海玉树地震 M7.1 级地震 [4-7], 2015 年尼泊尔 Mw7.8 级地震 $[8-12] 、 2017$ 年西藏米林 M6.9 级地震等。玉树地震、尼泊尔地震的典型震害图片如图 3 所示。

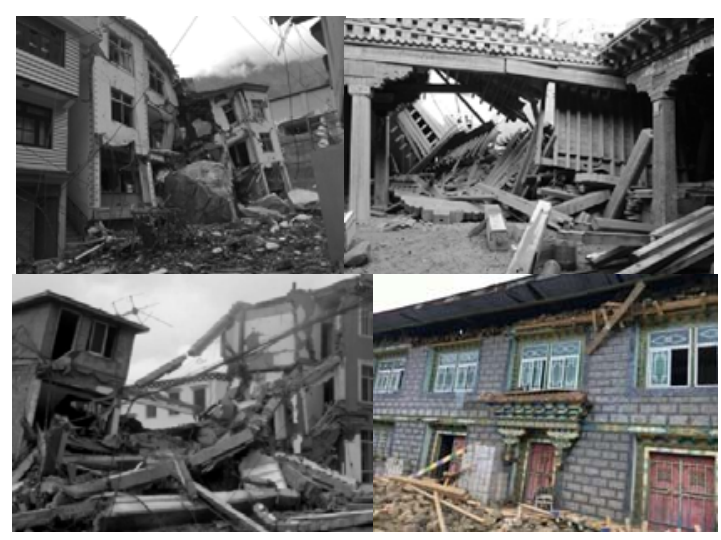

图 3 震害统计图片。上左: 尼泊尔地震后的西藏樟木, 烈度 8 度; 上右: 尼泊尔地震后的西藏吉隆, 烈度 8 度; 下左: 玉树 地震后的结古镇, 烈度 9 度; 下右: 米林地震后的林芝市, 烈 度 7 度。图片来源：高锦瑞等（2015）；白国良等（2011）; 曲哲, 杨永强（2015）

为分别计算地震造成的经济损失和人员伤亡，本文 对结构和人口都建立了易损性模型。四种建筑类型的结 构和人口易损性曲线如图 4 所示。其中 $\mathrm{PGA}<0.6 \mathrm{~g}$ 区间 的损失率的标准差为 0.3 , 其余区间标准差为 0.1 。

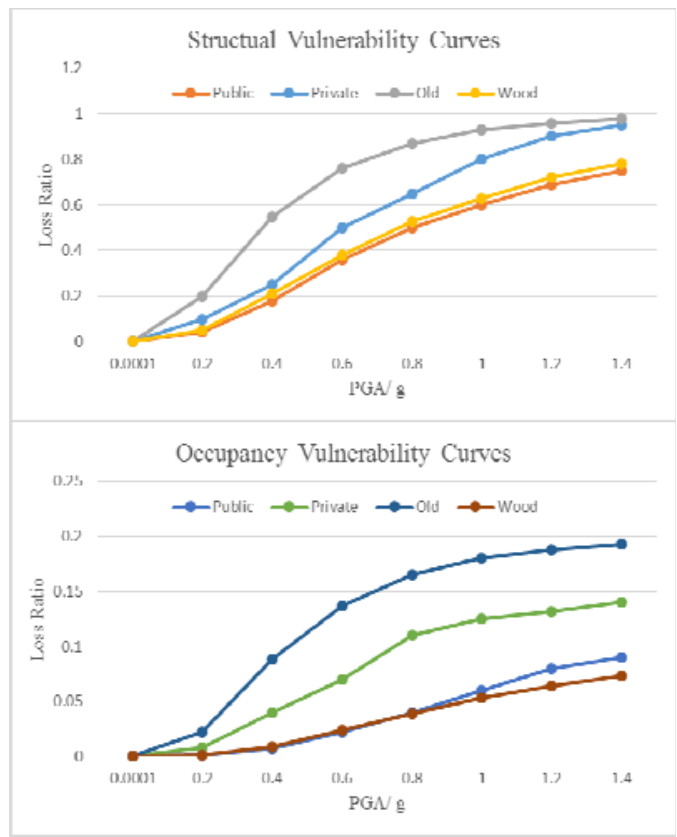

图 4 四种类型建筑的易损性曲线,

上：结构易损性；下：人口易损性

\section{$\mathrm{V}$. 设定地震及损失获取}

估算西藏东南部一次地震可能造成的损失情况。考 虑一次历史地震的重现。由图 1, 丽江在 1996 年发生了 7.0 级地震。本节模拟这次地震并产出迪庆 3 区县遭受 的损失情况。 
设定地震使用的断层参数如表 4 所示。发震断层设 为断裂。震级-破裂尺度的经验关系使用 Wells and Coppersmith (1994)[13]提出的关系, 地震动衰减关系使 用俞言祥等 (2013) [14]对中国地震动参数区划图使用 的衰减关系。模拟出的地震动分布如图 5 所示。

\section{表 4 模拟丽江地震的断层参数}

\begin{tabular}{c|c|c|c|c}
\hline 震级 & 震中位置 & 走向 $\left(^{\circ}\right)$ & 倾角 $\left(^{\circ}\right)$ & $\begin{array}{c}\text { 滑动角 }\left(^{\circ}\right. \\
{ }^{\circ}\end{array}$ \\
\hline 7.0 & $\begin{array}{r}100.3^{\circ} \mathrm{E}, \\
27.1^{\circ} \mathrm{N}\end{array}$ & 20 & 45 & 30 \\
& & & \\
\hline
\end{tabular}

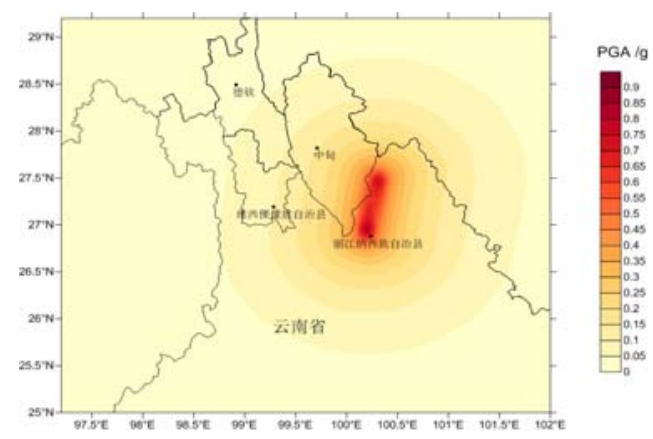

图 5 模拟丽江 7.0 级地震的地震动影响场

根据地震动影响场、承灾体规模模型和易损性模 型, 计算丽江地震在西藏东南部各县造成的建筑物轻度 以上破坏数量和人员伤亡分布。本文取轻度以上破坏为 建筑物损失率超过 $10 \%$ 。各县建筑物轻度以上破坏数量 和人员伤亡如表 5 和图 6 所示。可见, 如果丽江发生 7.0 级地震, 可能造成迪庆州 3 区县千余人的伤亡, 一 万余间房屋受损。

表 5 模拟丽江 7.0 级地震造成迪庆州各县人员伤亡列表

\begin{tabular}{c|c|c|c}
\hline 序号 & 区县 & 轻度以上破坏房屋 & 伤亡 \\
\hline 1 & 香格里拉市 & 7042 & 348 \\
2 & 德钦县 & 1493 & 81 \\
3 & 维西县 & 10397 & 974 \\
4 & 合计 & 18932 & 1403 \\
\hline
\end{tabular}

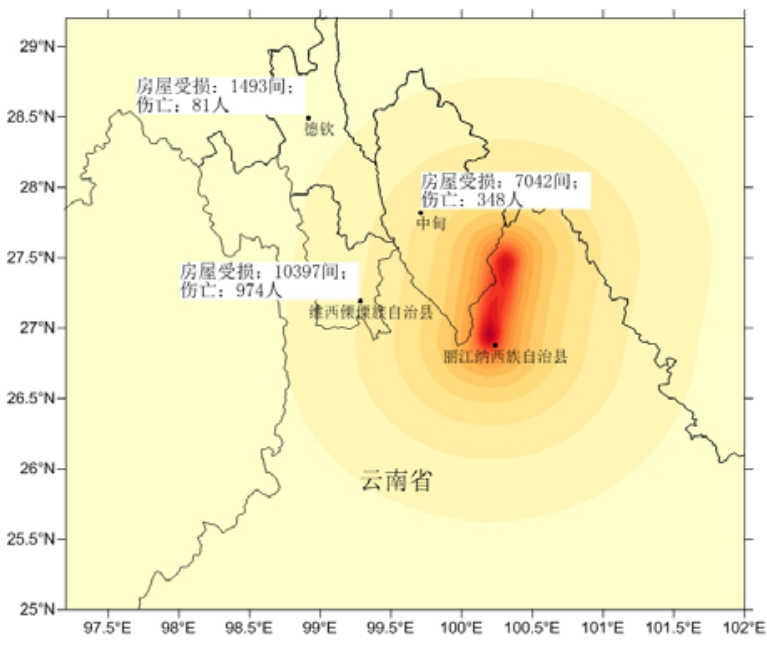

图 6 模拟丽江 7.0 级地震造成迪庆州各县损失情况

\section{VI. 结论与讨论}

本文在对迪庆州各县的建筑类型、数量、易损性调 查的基础上, 结合当地的人口和住房特点, 估计了不同 类型建筑在迪庆州的分布情况，建立了不同建筑物的结 构易损性和人口易损性模型, 并且估算了西藏东南部各 县分别在遭遇米林 M6.9 级地震和曲松-桑日 7.5 级地震 的人员伤亡和财产损失分布情况。本文得出的结论有:

(1) 西藏东南部的公建房和木结构房抗震性能较 好, 自建新房有一定的抗震能力, 老旧房的抗震能力较 差。

(2) 若丽江发生 7.0 级地震, 可能造成迪庆州 3 区县 千余人的伤亡，可能有 1.8 万余间房屋受损。

对以上结论, 本文做几点讨论:

(1) 本文建立承灾体规模模型的过程中，使用了诸 多假设，如假设全县人口均集中在县城、假设城乡的人 口/户数比例相同等。这些假设源自实地调研的认识, 多 数假设符合当地特点和实际, 类似方法可在有相同特点 地区推广。

(2) 本文估算不同建筑类型居住人口的方法, 类似 于“费米问题”[15]使用的估算方法, 虽不精确, 但应是 合理的。今后如能获取更精确的数据, 能改进本文的结 果。

(3) 本研究随机不确定性主要来自于易损性模型标 准差。认知不确定性主要来自于建立承灾体规模模型过 程中的假设, 以及建筑分类、抽样调查中认知不足造成 的不确定性。

致谢

本文由中国地震局地球物理研究所基本科研业务费 专项（DQJB17T04）、中国科学院国际合作局对外合作 重点项目（131551KYSB20160002）联合资助。

\section{参考文献}

[1]Li C L, Gao M T. 2019. Seismic Hazard Model Harmonization in Tienshan Area. Journal of Risk Analysis and Crisis Response, 9(2): 74-84. 
[2]国务院人口普查委员会, 国家统计局人口和就业统计司. 2010. 中国 2010 年人口普查资料. 北京: 中国统计出版社.

[3]李昌珑, 李宗超, 吕红山, 等. 2019. 基于三维图像模式识别的西藏 东南部地震灾害损失风险评估. 地球物理学报, 62(1): 393-410.

[4]谭明, 李洋, 胡伟华, 等. 2010. 青海玉树 7.1 级地震房屋建筑震害 调查和分析. 内陆地震, 24(2): 173-179.

[5]秦松涛, 李智敏, 谭明, 等. 2010. 青海玉树 7. 1 级地震震害特点分 析及启示. 灾害学, 25(3): 65-70.

[6]黄思凝, 袁一凡, 孟庆利, 等. 2011. 由玉树地震结构震害看村镇房 屋抗震. 世界地震工程, 27(2): 77-82.

[7]白国良, 薛冯, 徐亚洲. 2011. 青海玉树地震村镇建筑震害分析及 减灾措施. 西安建筑科学学报 (自然科学版), 43(3): 309-315.

[8]高锦瑞, 尼玛, 文升梁, 等. 2015. 尼泊尔 8.1 级地震对中国西藏地 区造成的震害特征分析. 震灾防御技术，10(4): 961一968.

[9]王晓青, 黄树松, 丁香, 等. 2015. 尼泊尔 8.1 级地震建筑物震害遥 感提取与分析. 震灾防御技术, $10(3)$ : 481-490.

[10]曲哲, 杨永强. 2015. 尼泊尔自建民居在 2015 年地震序列中的震害. 地震工程与工程振动, 35(4): 51-59.

[11]张吴宇, 王涛, 林旭川, 等. 2016. 尼泊尔 8.1 级地震钢筋混凝土框 架典型震害及讨论. 工程力学, 33(9): 59-68.

[12]潘毅, 王忠凯, 时胜杰, 等. 2017. 尼泊尔 8.1 级地震加德满都一樟 木沿线民居震害调查与分析. 湖南大学学报 (自然科学版), 44(3): 35-44.

[13]Wells D L, Coppersmith K J. 1994. New empirical relationships among magnitude, rupture length, rupture width, rupture area, and surface displacement. Bulletin of the Seismological Society of America, 84(4): 974-1002.

[14]俞言祥, 李山有, 肖亮. 2013. 为新区划图编制所建立的地震动衰 减关系. 震灾防御技术, 8(1): 24-33.

[15]周小奋. 2011. 费米问题三例. 物理通报, 2011(5): 85-88. 